\title{
Serotonergic Efferent Nerve Fibers in the Retinal Plexiform Layer of the Abalone
}

\author{
Seiki Kataoka, Toshi Yuki Yamamoto and Ryogo Yui* \\ Department of Anatomy, Tohoku University School of \\ Medicine, Sendai 980, and *Department of Anatomy, \\ Niigata University School of Medicine, Niigata 951
}

\begin{abstract}
Kataoka, S., Yamamoto, T.Y. and Yui, R. Serotonergic Efferent Nerve Fibers of the Retinal Plexiform Layer of the Abalone. Tohoku J. exp. Med., 1987, 153 (4), 335-346 - Serotonin (5-HT)-immunohistochemistries at light- and electron-microscopic levels, using rabbit anti-5-HT serum (\#1234), were applied to the whole head and only to the eye of the abalone, respectively. Peroxidaseantiperoxidase and fluorescein isothiocyanate methods were used for the lightmicroscopic immunohistochemistries. Many immunoreactive nerve fibers were demonstrated in the outer zone of the retinal plexiform layer, small optic nerve fiber bundles, the optic nerve trunk and the cerebral ganglion. Immunoreactive somata were observed only in the cerebral ganglion. Accordingly the immunoreactive fibers in the retinal plexiform layer are considered to be efferent. Cored vesicles in the retinal plexiform layer demonstrated by both conventional chemofixation and a rapid-freeze-substitution method showed strong immunoreactivities localized within their limiting membrane. The same fibers also contained small clear vesicles. They are considered to be different from larger clear vesicles in non-immunoreactive fibers reportedly containing acetylcholine. The function of the efferent fibers remains to be elucidated. - efferent nerve; retinal plexiform layer; abalone; serotonin (5-HT) immunohistochemistry ; rapid-freeze-substitution
\end{abstract}

In the abalone retinal plexiform layer, two types of synaptic or neural vesicles, clear (C-) and dense-cored (D-), were classified by Tonosaki (1967). Although Tonosaki (1967) suggested the C-vesicles, about $50 \mathrm{~nm}$ in diameter, to be cholinergic ones, no comment was added on the neurotransmitter of the D-vesicles, $40-100 \mathrm{~nm}$ in diameter. The existence of cholinergic nerve fibers in this tissue was later confirmed by acetylcholinesterase (ACh'esterase) histochemistry (Tsukahara et al. 1974).

Received September 2, 1987 ; accepted for publication October 23, 1987.

Abbreviations used in this paper: ACh, acetylcholine; BSA, bovine serum albumin ; $\mathrm{C}$-, clear or only clear vesicles-containing; D-, dense-cored or dense-cored vesiclescontaining; EM, electron microscopic(-scopy); FITC, fluorescein isothiocyanate; 5-HT, 5-hydroxytryptamine; LM, light microscopic ; PAP, peroxidase-antiperoxidase ; PB, phosphate buffer; PBS, phosphate-buffered saline; RFS, rapid-freeze-substitution. 
Serotonin (5-hydroxytryptamine, 5-HT) was reviewed to be a neurotransmitter that is abundantly distributed particularly in molluscan nervous tissues (Gerschenfeld 1973; De Biasi and Vitellaro-Zuccarello 1987). The retina in Aplysia, which belongs to the same class as abalone, also contains 5-HTimmunoreactive axons from cerebral ganglion (Goldstein et al. 1984). So, and from our ultrastructural observations, we hypothesized that the chemical substance in the D-vesicles is 5-HT. In order to confirm it, we conducted light- (LM) and electron-microscopic (EM) immunohistochemistries. The origin of the Dvesicles-containing (D-) nerve fibers was also intended to be clarified.

\section{Materials and Methods}

Whole heads and eyestalk tips bearing eyes of prosobranchiate gastropod abalones, Nordotis discus, were used for LM and EM studies, respectively. Cerebral ganglia were identified according to the description of Simroth (1896-1907).

\section{Conventional electron microscopy (EM)}

The snipped eyestalks were bisected through the pupil and fixed in $2 \%$ glutaraldehyde buffered with phosphate-buffered saline (PBS) ( $\mathrm{pH} \mathrm{7.4)} \mathrm{for} 1.5 \mathrm{hr}$, rinsed in PBS for $30 \mathrm{~min}$, and post-fixed in ice-cold PBS-buffered $1 \%$ osmium tetroxide for $2 \mathrm{hr}$. Osmolarities of the fixatives and rinse were adjusted to $900-1,000 \mathrm{mOsm}$ by changing concentrations of the PBS $(0.07-0.08 \mathrm{M} \mathrm{PB}$ and $2-2.4 \% \mathrm{NaCl})$. The fixed eyes were dehydrated in graded concentrations of ethanol, passed through propylene oxide, and embedded in epoxy resin (using epon-812 ; Serva, Heidelberg, FRG). Ultrathin sections were mounted on copper grids, double-stained with uranyl acetate for $10 \mathrm{~min}$ and lead citrate for $5 \mathrm{~min}$, and observed in an electron microscope (H-500; Hitachi, Tokyo) at $100 \mathrm{kV}$ of accelerating voltage.

\section{Rapid-freeze-substitution (RFS) preparation}

The bisected eyes were frozen with a rapid-freezing apparatus of the liquid nitrogencooled copper-contact type (RF-2 ; Eiko, Mito), and kept in liquid nitrogen for several 10 min. The specimens were then freeze-substituted in $2 \%$ osmium tetroxide in acetone at $-80^{\circ} \mathrm{C}$ (either in a dry ice-acetone mixture or in a deep freezer) for about 2 days. After gradual increase of the substitution temperature to $4^{\circ} \mathrm{C}$ during $3-4 \mathrm{hr}$, the specimens were passed through several changes of cold pure acetone and embedded in epon. Ultrathin sections were mounted on copper or nickel grids. The copper grid-mounted sections were double-stained and observed.

\section{LM immunohistochemistry}

The heads were median-sectioned and fixed in a solution of $4 \%$ paraformaldehyde, $0.1 \%$ glutaraldehyde and $0.1 \mathrm{M} \mathrm{PB}(\mathrm{pH} 7.4$ ), with or without $8 \%$ sucrose, for $3 \mathrm{hr}$ at room temperature. They were usually rinsed in cold $0.1 \mathrm{M} \mathrm{PB}$ 'ed $20 \%$ and $30 \%$ sucrose for $2 \mathrm{hr}$ each, and then embedded in cryomatrix and frozen at $-80^{\circ} \mathrm{C}$. Serial horizontal sections, 8 $12 \mu \mathrm{m}$ in thickness, were prepared with a cryostat (Cryo Tome 1500; Lipshaw, Detroit, MI, USA) and mounted on glass slides coated with poly-L-lysine.

Serotonin-immunoreactivities were examined by both enzyme antibody (peroxidaseantiperoxidase, PAP) and fluorescent antibody methods. Cold 0.01 M PBS containing $0.85 \% \mathrm{NaCl}$ ( $\mathrm{pH} 7.2$ ) was used as rinses between all the following steps. Before getting the proper dilutions of all antibodies with $1 \%$ bovine serum albumin (BSA) (Wako, Osaka), various dilutions were examined. 1) The cryosections were dried, 2) intrinsic peroxidases therein were blocked in $0.3 \% \mathrm{H}_{2} \mathrm{O}_{2}$ in methanol for $30 \mathrm{~min}$, and then 3) non-specific back ground staining was minimized with goat whole serum (1:20; Cappel, West Chester, PA, 
USA) for $20 \mathrm{~min}$. For the PAP method, 4) the sections were incubated with primary antibody, anti-5-HT serum (\#1234) which was raised in rabbits (Yui and Fujita 1986), (1: $1,000)$ or BSA (for control) overnight, 5) with swine anti-rabbit immunoglobulin $(1: 30$; Dakopatts, Glostrup, Denmark) for $1 \mathrm{hr}$, and then 6) with rabbit PAP complex (1:50; Dakopatts) for $1 \mathrm{hr}$. 7) They were immersed in a solution of $0.02 \% 3,3^{\prime}-$ diaminobenzidine-4 $\mathrm{HCl}$ (Dojindo, Kumamoto), $0.005 \% \mathrm{H}_{2} \mathrm{O}_{2}$ and $0.05 \mathrm{M}$ Tris-HCl buffer $(\mathrm{pH} \mathrm{7.6)}$ for $5 \mathrm{~min}$, and 8) counterstained with veronal acetate-buffered $(\mathrm{pH} 4.4) 1 \%$ methyl green (Chroma, Stuttgart, FRG) for a few hr. The immuno- and counterstained sections were mounted with epon, and observed with a microscope (AHBT-513; Olympus, Tokyo).

Dilutions of antibodies for the immunofluorescence were $\left.4^{\prime}\right) 1: 100$ of \#1234 and 5') $1: 40$ of swine anti-rabbit immunoglobulin conjugated with fluorescein isothiocyanate (FITC) (Dakopatts). The FITC-labelled and glycerin (Dotite Luminasol; Dojindo)mounted sections were observed using the microscope equipped with a fluorescence unit (AH2-RFL-1, incident illumination type; Olympus). Exciting and barrier filters used were BP490 plus EY455 and O515, respectively.

To check the specificity of the immunostaining, \#1234 was incubated for $24 \mathrm{hr}$ at $4^{\circ} \mathrm{C}$ either with 5-HT (10-20 $\mu \mathrm{g} / \mathrm{ml}$ diluted antiserum) or with 5-HT-BSA conjugate (10 $\mu \mathrm{g}-1.6$ $\mathrm{mg} / \mathrm{ml}$ diluted antiserum). Although the immunostaining was unchanged when \#1234 treated with 5-HT alone was used as the first layer, it was abolished when the antiserum preabsorbed with 5-HT-BSA conjugate was used.

\section{EM immunohistochemistry}

RFS-prepared and nickel grid-mounted sections were etched with $10 \% \mathrm{H}_{2} \mathrm{O}_{2}$ for $10 \mathrm{~min}$ and processed according to the same steps as the LM PAP method other than the dilution of primary antibody $(1: 400)$, benzidine reaction time $(10 \mathrm{~min})$, and electron staining (double-stained for $1 \mathrm{~min}$ each). EM observations were done at $75 \mathrm{kV}$ of accelerating voltage.

\section{Morphometry}

Several electron micrographs of the retinal plexiform layer from conventionally fixed and RFS'ed specimens were sampled at random. Their final magnifications were $\times 68,000$ and $\times 90,000$, respectively. Using a two-dimensional image-analyzer system (Cosmozone-I ; Nikon, Tokyo), diameters of a few types of synaptic vesicles thereon were measured and the statistical differences among their mean values were examined by Student's $t$-test.

\section{Results}

\section{LM immunohistochemistry}

Both PAP and FITC methods demonstrated the immunoreactivities in the outer zone of the plexiform layer and small optic nerve fiber bundles, but neither in the inner plexiform layer nor in the retinal cellular layer (Fig. 1). The immunoreactive varicose nerve fibers were traced proximally along the optic nerve to the medulla of cerebral ganglion and to the anterior part of cerebral commissure interconnecting a pair of the ganglia (Figs. 2-4). In the anterolateral and dorsal cortical region of the cerebral ganglion were scattered fusiform, pyramidal and spherical immunoreactive somata, $15-20 \mu \mathrm{m}$ in major axis, which were oriented perpendicularly to the ganglion surface, among numerous non-reactive granular cells (Fig. 3). Other neural elements such as some tentacular nerve fibers were also immunoreactive. 


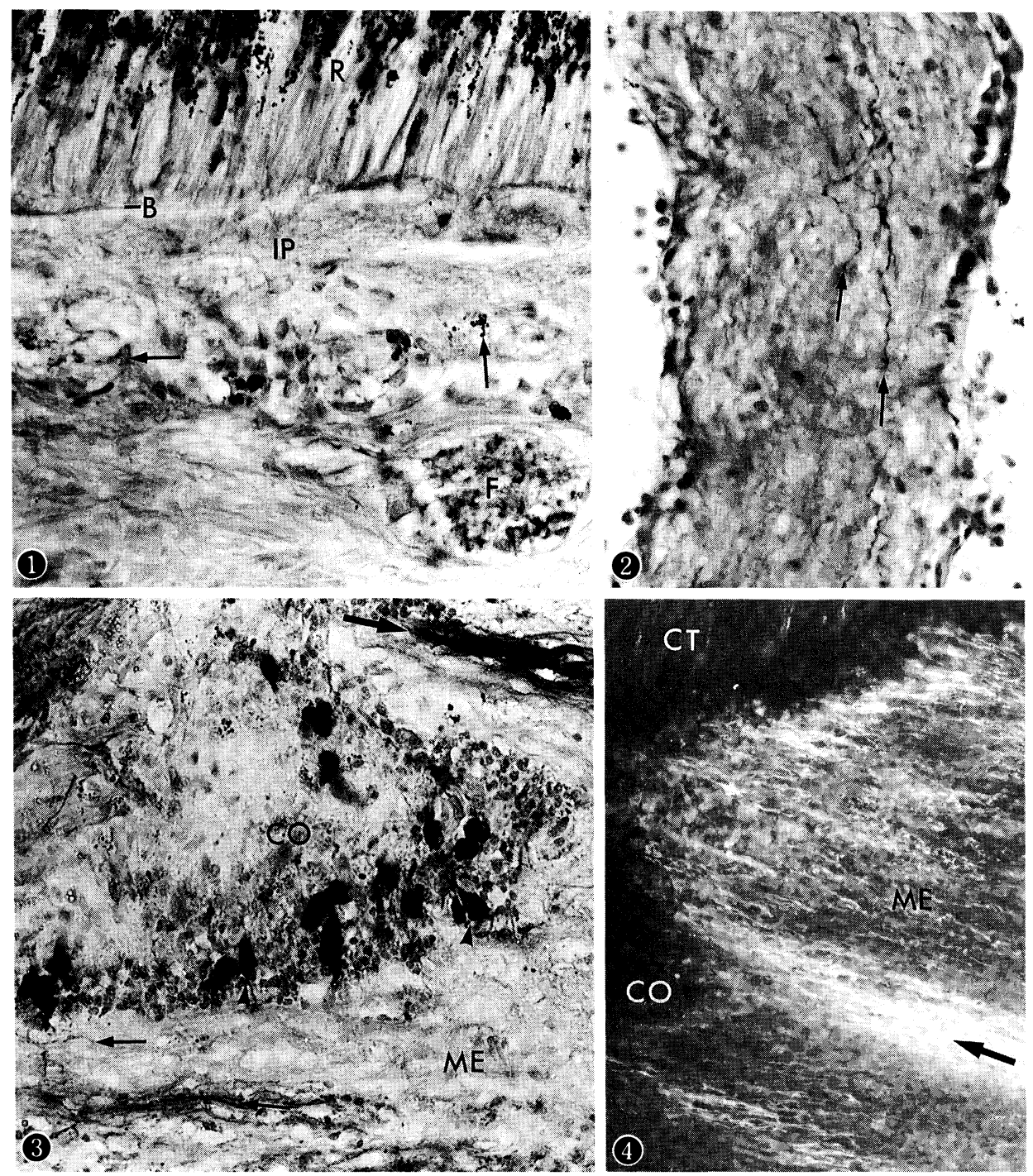

Figs. 1-3. Light micrographs of retinal plexiform layer (Fig. 1), optic nerve (Fig. 2) and cerebral ganglion (Fig. 3) which were immunostained by PAP method. 5 -HT-immunoreactive nerve fibers are indicated by arrows.

Fig. 1. B, basement membrane; F, nerve fiber bundle containing immunoreactive fibers; IP, inner plexiform layer showing no immunoreactivity; $R$, retinal cellular layer containing numerous pigment granules. $\times 540$.

Fig. $2 . \times 330$.

Fig. 3. CO, cortex of cerebral ganglion containing immunoreactive neuronal somata (arrowheads); ME, medulla of cerebral ganglion containing a strongly immunoreactive nerve fiber bundle (thick arrow) as well as many fine fibers. $\times 270$.

Fig. 4. Light micrograph of ventral part of cerebral ganglion. Medulla (ME) contains numerous 5-HT-immunofluorescent nerve fibers. Thick arrow shows a strongly immunofluorescent fiber bundle. CO, cortex without immunofluorescent neuronal somata; CT, circumganglional tissue. $\times 170$. 


\section{EM}

In the conventionally chemofixed specimens, the retinal plexiform layer contained two types of nerve fibers; one (C-fiber) containing only $\mathrm{C}$-vesicles, about $70 \mathrm{~nm}$ in diameter, and the other D-fiber containing D-vesicles, $95 \mathrm{~nm}$, together with 105-nm granular-cored vesicles and 60-nm C-vesicles (Fig. 5). Their detailed sizes are shown in Fig. 7 and Table 1. All the C-vesicles showed distinct limiting membranes (Fig. 5). The D- and granular-cored vesicles, however, showed an indistinct inner leaflet and a partially indistinct (probably ruptured) unit membrane, respectively.

Only a few D-fibers were found apposed to the bases of photoreceptor and supporting cells and many in the plexiform layer, with much more in its outer zone. The typical synaptic features of at least D-fibers, with thickened membranes and the cleft as well as clustered vesicles, were occasionally observed upon probable photoreceptor cell axons containing C-vesicles (Inset of Fig. 5). The nerve fibers also contained mitochondria, dilated agranular endoplasmic reticulum and filamentous structures.

In the RFS'ed specimens, similar two types of fibers were observed, although the cored vesicles were of only one type, i.e., vesicles with thin-haloed and less dense core (Fig. 6). The matrix of mitochondria was rather dense. Microtubules were also seen in some fibers.

5-HT-immunoreactivities were localized mostly within vesicles whose diameter ranged from $<50 \mathrm{~nm}$ to $140 \mathrm{~nm}$ (Figs. 8 and 9). The fibers with such immunoreactive vesicles also contained small C-vesicles, about $60 \mathrm{~nm}$ in diameter, but not non-immunoreactive larger cored vesicles. Non-immunoreactive fibers contained almost uniform C-vesicles, $70 \mathrm{~nm}$ in diameter (Fig. 10). The sizes of three types of vesicles are shown in Fig. 7 and Table 1.

No EM observations of optic nerves and cerebral ganglia have yet been done.

\section{Discussion}

\section{Retinal efferent nerve fibers}

5-HT-immunoreactive nerve fibers in the abalone retina are considered to be efferent ones from the cerebral ganglion, only where, in the photoreceptive system, were found the immunoreactive somata. Efferent nerve fibers to the retina and the related structure obviously or probably from the cerebral ganglion and the corresponding structure were also reported in some other mollusks ; serotonergic in the opistobranchiate gastropod, Aplysia (Nadakavukaren et al. 1986), peptidergic (such as molluscan cardioexcitatory peptide) in the related gastropod, Bulla (Roberts and Moore 1987), without reference to any neurotransmitter in the pulmonate gastropod, Helix (Mortensen and Eakin 1974), and dopaminergic in some cephalopods (Tasaki et al. 1982 ; Silver et al. 1983).

In the octopus retina, an inhibition of afferent spike discharges by the 

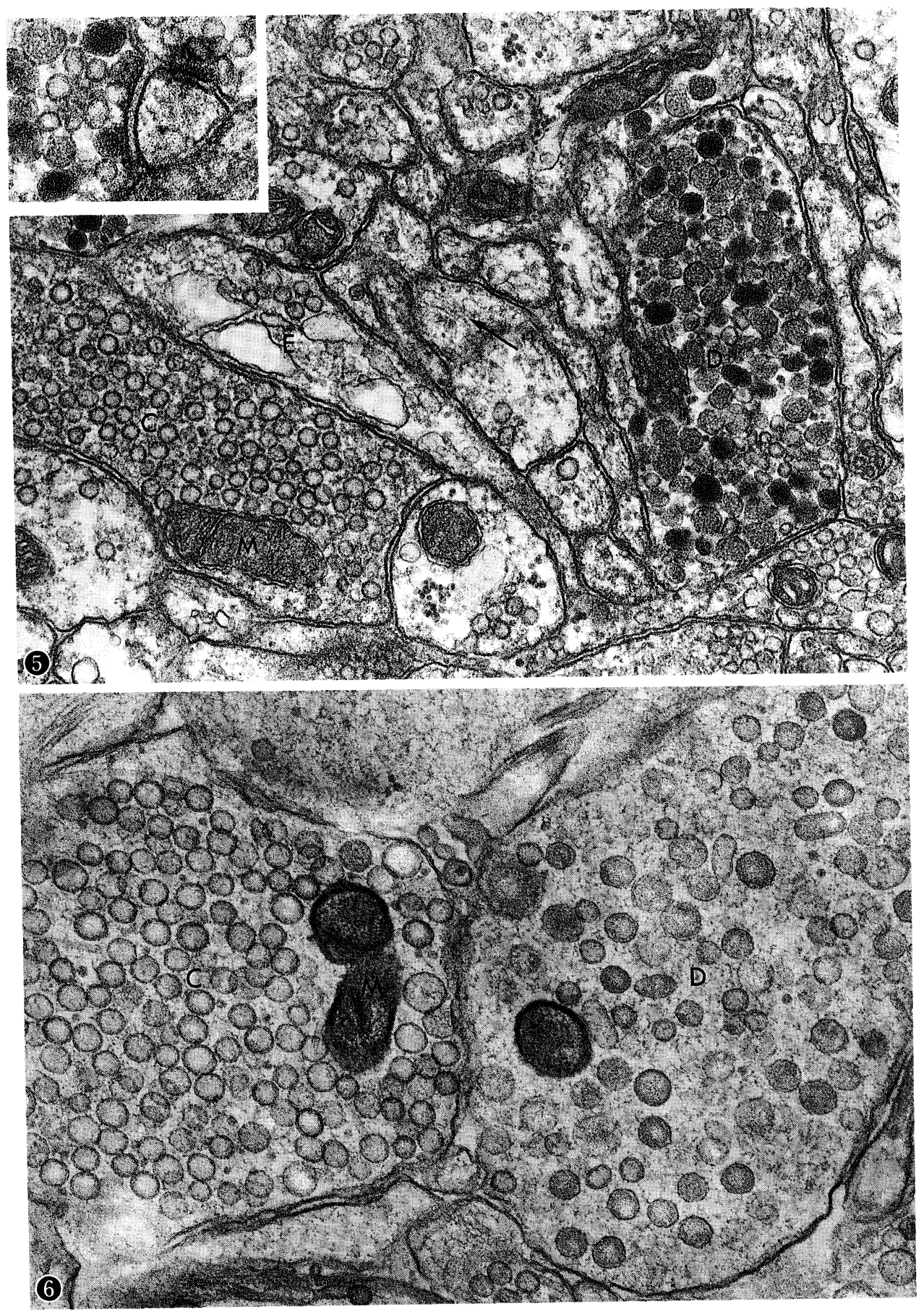


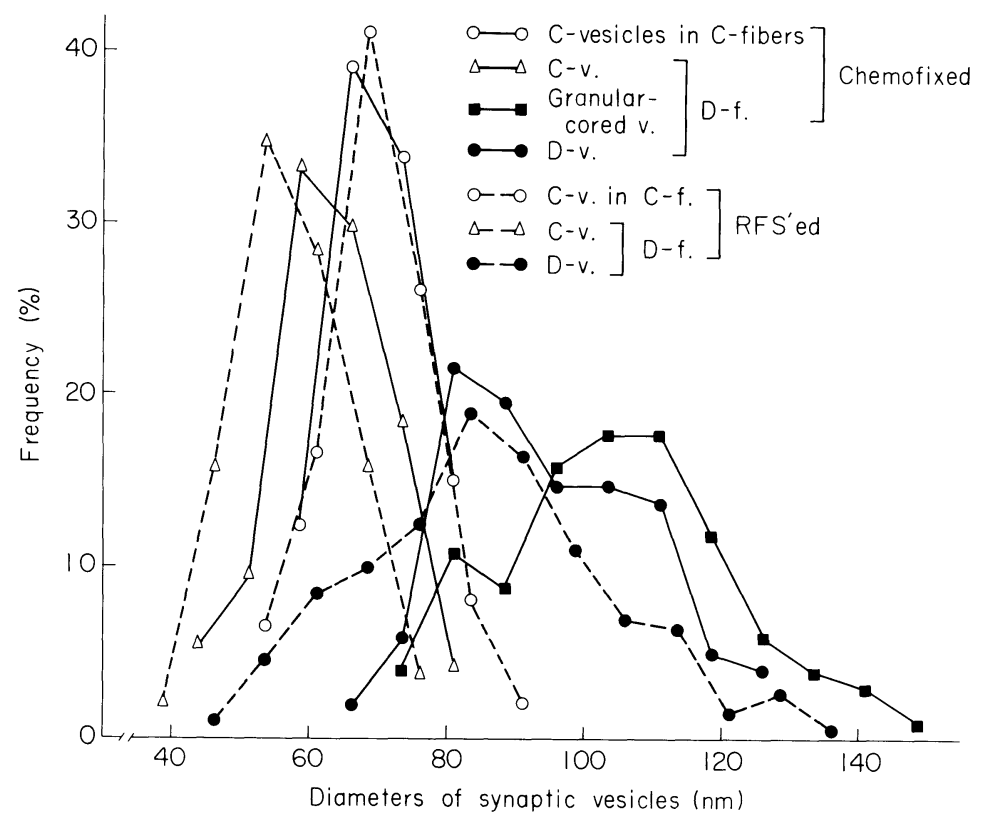

Fig. 7. Frequency curves of diameters of synaptic vesicles in chemofixation and RFS.

efferents reportedly improves the spatial resolving ability, together with a lateral inhibition by axon collaterals of the photoreceptor cells (Tasaki et al. 1982; Suzuki and Tasaki 1983). The efferents innervating the musculature of optic capsule and capsular strands in Helix are considered to be involved in focusing images on the retina by changing the shape of the eye (Mortensen and Eakin

TABLE 1. Mean diameters of synaptic vesicles

\begin{tabular}{cccc}
\hline \multirow{2}{*}{ Fiber } & \multirow{2}{*}{ Vesicle } & \multicolumn{2}{c}{ Preparation methods } \\
\cline { 3 - 4 } & & Chemofixation & RFS \\
\hline C- & C- & $70.0 \pm 6.3^{*}(150) \dagger$ & $69.8 \pm 7.7(200)$ \\
& C- & $62.9 \pm 8.7(150)$ & $57.6 \pm 7.8(220)$ \\
D- & Granular-cored & $104.7 \pm 16.8(100)$ & None \\
& D- & $95.3 \pm 14.0(100)$ & $86.0 \pm 18.2(200)$ \\
\hline
\end{tabular}

* Mean \pm S.D. $(\mathrm{nm})$.

$\dagger$ Number of measured vesicles.

Figs. 5 and 6. Electron micrographs of chemofixed (Fig. 5) and RFS'ed (Fig. 6) retinal plexiform layer. C, C-fiber; D, D-fiber; M, mitochondria.

Fig. 5. Note the distinct limiting membranes of $\mathrm{C}$-vesicles compared with $\mathrm{D}$ - and granular-cored vesicles in D-fiber. Arrow indicates filamentous structures. E, dilated agranular endoplasmic reticulum. $\times 35,900$.

Inset shows two synapses upon a fiber. $\times 51,500$.

Fig. 6. Note the lower electron density of cores of D-vesicles and higher density of mitochondria. $\times 51,500$. 


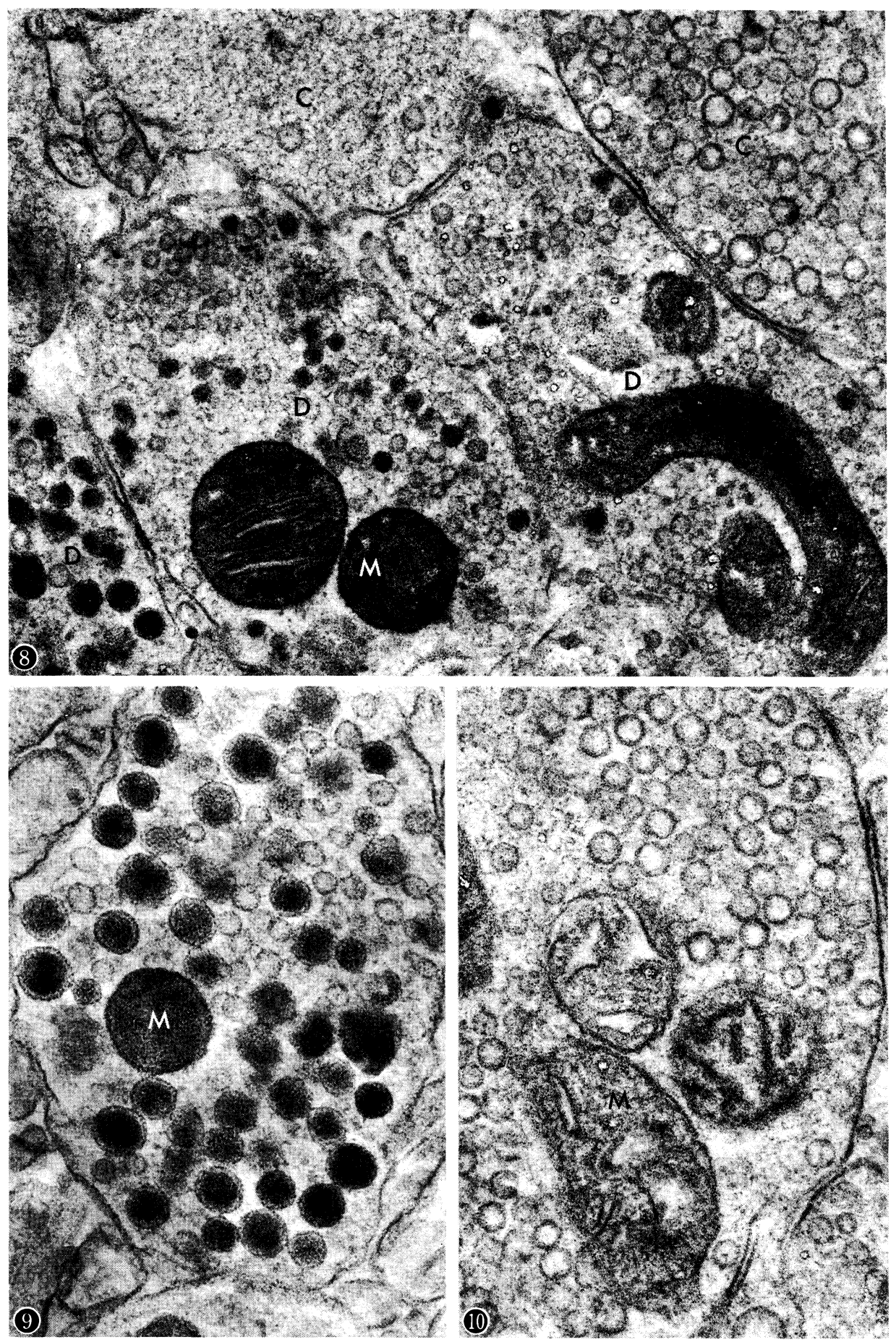


1974). Those in the opistobranchs are hypothesized to influence the circadian clock in the eye (Nadakavukaren et al. 1986; Roberts and Moore 1987). Although light-generated diurnal changes in the structure of abalone photoreceptors were reported (Kataoka and Yamamoto 1981), there has been no more information on the biological clock of this animal. The function of abalone's serotonergic retinal efferents remains to be elucidated.

Barlow and colleagues have studied functional and structural circadian rhythms in Limulus photoreceptors, which are reported to be mediated by efferent optic nerve activity which in turn to be generated by a cerebral circadian clock (e.g., Barlow 1983; Chamberlain and Barlow 1984). In the blowfly visual system, retinal efferents arising from the optic lobe were shown to contain gammaamino butyric acid and suggested to provide major afferents with inhibitory inputs (Datum et al. 1986).

The serotonergic neurons were also reported in other nervous systems of invertebrates such as Microstomum lineare (Reuter et al. 1986), earthworm (Spörhase-Eichmann et al. 1987a, b), blowfly (Nässel and Elekes 1985; Ohlsson and Nässel 1987) and honeybee (Rehder et al. 1987). In the vertebrate retina, they appear to correspond to amacrine cells (e.g., in the carp, Hayashi et al. 1986).

\section{Types of synaptic vesicles and neurotransmitters}

Two types of synaptic vesicles, C- and cored, are roughly classified both in chemofixed and RFS'ed retinal plexiform layer in the abalone. C-vesicles are further classified into those contained in the C- and D-fibers, whose diameters are significantly different $(p<0.01)$. As mentioned by Tonosaki (1967), chemofixation demonstrated two groups of cored vesicles, smaller D- and larger granular-cored (or less D-), showing significantly different $(p<0.01)$ diameters from each other. In RFS, however, there were observed only one type of less D(without immunostaining) and 5-HT-immunoreactive vesicles whose diameter is significantly different $(p<0.01)$ from granular-cored vesicles and not from Dvesicles in chemofixation. There is a possibility that, without the corresponding ones in RFS, larger granular-cored vesicles in chemofixation are artificial structures of swollen D-vesicles with a probably ruptured limiting membrane. Although most immunoreactive vesicles are considered to be cored vesicles, some larger C-vesicles in D-fibers may also be immunoreactive, because the diameter of the $\mathrm{C}$-vesicles in D-fibers in RFS followed by immunostaining is significantly

\footnotetext{
Figs. 8-10. Immuno-electron micrographs of retinal plexiform layer. C, C-fiber ; D, D-fiber containing 5-HT-immunoreactive vesicles; M, mitochondria showing higher electron density especially in D-fiber.

Fig. $8 . \times 50,500$.

Fig. 9. D-fiber contains two types of smaller C- and larger immunoreactive D-vesicles. D-vesicle has haloed core limited by a thin membrane. $\times 59,100$.

Fig. 10. C-fiber contains distinct limiting membrane-bounded C-vesicles of uniform size. $\times 59,100$.
} 
smaller $(p<0.01)$ than that in chemofixation. In the small $\mathrm{C}$-vesicles may otherwise be contained some other neurotransmitters.

A serotonergic varicosities identified by EM autoradiography in the Aplysia central nervous system contains 3 types of vesicles (Shkolnik and Schwartz 1980). D- and small C-vesicles among them may correspond to the similar 2 types of vesicles in the abalone retina.

The C-vesicles in photoreceptor cell axons in the abalone reportedly contain ACh, which mediate the lateral inhibition (Tsukahara et al. 1974). However, before concluding that ACh-containing $\mathrm{C}$-vesicles are those only in C-fibers, the choline acetyltransferase immunohistochemistry at EM level, which is a more reliable strategy for staining cholinergic neurons than the ACh'esterase histochemistry (Pourcho and Osman 1986), must be experimented.

For the present, anyhow, only two types of nerve fibers, probable cholinergic C- and serotonergic D-, can safely be classified in the abalone retinal plexiform layer. This is different from the case in the Bulla neuropil collared by circadian clock neurons, where is found, in addition to the morphologically similar two types of nerve fibers, the third type containing large very D-vesicles (Jacklet and Colquhoun 1983).

\section{RFS used in EM immunohistochemistry}

Application of RFS to 5-HT immunohistochemistry at EM level is considered to be suitable from the following reasons ; 1) the preservation of ultrastructure is good, 2) immunoreactivities are moderately kept in situ even after eponembedding, 3) positive immunoreactivities are easily known in contrast to low electron density of the vesicles' core without immunostaining. Such localization is in a striking contrast to that of some neuropeptides in the cytoplasm and/or vesicles after immunostained by other methods (e.g., Kondo et al. 1986).

\section{Acknowledgments}

This study was partly supported by Grant for Scientific Research No. 62570001 from the Ministry of Education, Science and Culture, Japan.

\section{References}

1) Barlow, R.B., Jr. (1983) Circadian rhythms in the Limulus visual system. $J$. Neurosci., 3, 856-870.

2) Chamberlain, S.C. \& Barlow, R.B., Jr. (1984) Transient membrane shedding in Limulus photoreceptors: Control mechanisms under natural lighting. J. Neurosci., 4, 2792-2810.

3) Datum, K.-H., Weiler, R. \& Zettler, F. (1986) Immunocytochemical demonstration of $\gamma$-amino butyric acid and glutamic acid decarboxylase in R7 photoreceptors and $\mathrm{C} 2$ centrifugal fibers in the blowfly visual system. J. comp. Physiol. A, 159, 241-249.

4) De Biasi, S. \& Vitellaro-Zuccarello, L. (1987) Distribution of 5HT-immunoreactivity in the pedal ganglion of Mytilus galloprovincialis. A light- and electron-microscopic study. Cell Tissue Res., 249, 111-116. 
5) Gerschenfeld, H.M. (1973) Chemical transmission in invertebrate central nervous systems and neuromuscular junctions. Physiol. Rev., 53, 1-119.

6) Goldstein, R., Kistler, H.B., Jr., Steinbusch, H.W.M. \& Schwartz, J.H. (1984) Distribution of serotonin-immunoreactivity in juvenile Aplysia. Neuroscience, 11, $535-547$.

7) Hayashi, T., Hirose, G., Kawata, M. \& Sano, Y. (1986) Cytological features of serotonin-containing neurons and their processes in the retina of the carp (Cyprinus carpio). An immunohistochemical study using flat-mount preparations. Histochemistry, 84, 423-425.

8) Jacklet, J.W. \& Colquhoun, W. (1983) Ultrastructure of photoreceptors and circadian pacemaker neurons in the eye of a gastropod, Bulla. J. Neurocytol., 12,673696.

9) Kataoka, S. \& Yamamoto, T.Y. (1981) Diurnal changes in the fine structure of photoreceptors in an abalone, Nordotis discus. Cell Tissue Res., 218, 181-189.

10) Kondo, H., Kuramoto, H. \& Fujita, T. (1986) An immuno-electron-microscopic study of the localization of VIP-like immunoreactivity in the adrenal gland of the rat. Cell Tissue Res., 245, 531-538.

11) Mortensen, C. \& Eakin, R.M. (1974) Efferent neurites to capsular muscles in the eye of a snail, Helix aspersa. J. Ultrastruct. Res., 49, 286-294.

12) Nadakavukaren, J.J., Lickey, M.E. \& Jordan, W.P. (1986) Regulation of the circadian clock in the Aplysia eye: Mimicry of neural action by serotonin. J. Neurosci., 6, 14-21.

13) Nässel, D.R. \& Elekes, K. (1985) Serotonergic terminals in the neural sheath of the blowfly nervous system: Electron microscopical immunocytochemistry and 5,7dihydroxytryptamine labelling. Neuroscience, 15, 293-307.

14) Ohlsson, L.G. \& Nässel, D.R. (1987) Postembryonic development of serotoninimmunoreactive neurons in the central nervous system of the blowfly, Calliphora erythrocephala. I. The optic lobes. Cell Tissue Res., 249, 669-679.

15) Pourcho, R.G. \& Osman, K. (1986) Acetylcholinesterase localization in cat retina : A comparison with choline acetyltransferase. Exp. Eye Res., 43, 585-594.

16) Rehder, V., Bicker, G. \& Hammer, M. (1987) Serotonin-immunoreactive neurons in the antennal lobes and suboesophageal ganglion of the honeybee. Cell Tissue Res., 247, 59-66.

17) Reuter, M., Wikgren, M. \& Lehtonen, M. (1986) Immunocytochemical demonstration of 5-HT-like and FMRF-amide-like substances in whole mounts of Microstomum lineare (Turbellaria). Cell Tissue Res., 246, 7-12.

18) Roberts, M.H. \& Moore, R.Y. (1987) Localization of neuropeptides in efferent terminals of the eye in the marine snail, Bulla gouldiana. Cell Tissue Res., 248, 67-73.

19) Shkolnik, L.J. \& Schwartz, J.H. (1980) Genesis and maturation of serotonergic vesicles in identified giant cerebral neuron of Aplysia. J. Neurophysiol., 43, 945-967.

20) Silver, S.C., Patterson, J.A. \& Mobbs, P.G. (1983) Biogenic amines in cephalopod retina. Brain Res., 273, 366-368.

21) Simroth, H. (1896-1907) H.G. Bronn's Klassen und Ordnungen des Tier-reichs, wissenschaftlich dargestellt in Wort und Bild, Bd. 3. Mollusca, Abt. 2. Gastropoda prosobranchia. C.F. Winter'sche Verlagshandlung, Leipzig.

22) Spörhase-Eichmann, U., Gras, H. \& Schürmann, F.-W. (1987a) Patterns of serotonin-immunoreactive neurons in the central nervous system of the earthworm Lumbricus terrestris L. I. Ganglia of the ventral nerve cord. Cell Tissue Res., 249, 601-614.

23) Spörhase-Eichmann, U., Gras, H. \& Schürmann, F.-W. (1987b) Patterns of serotonin-immunoreactive neurons in the central nervous system of the earthworm Lumbricus terrestris L. II. Rostral and caudal ganglia. Cell Tissue Res., 249, 625632. 
24) Suzuki, H. \& Tasaki, K. (1983) Inhibitory retinal efferents from dopaminergic cells in the optic lobe of the octopus. Vision Res., 23, 451-457.

25) Tasaki, K., Tsukahara, Y., Suzuki, H. \& Nakaye, T. (1982) Two types of inhibition in the cephalopod retina. In: Neurotransmitters in the Retina and the Visual Centers (Biomed. Res., 3, Suppl.), edited by A. Kaneko, N. Tsukahara \& K. Uchizono, Biomedical Research Foundation, Tokyo, pp. 41-44.

26) Tonosaki, A. (1967) Fine structure of the retina in Haliotis discus. Z. Zellforsch. mikrosk. Anat., 79, 469-480.

27) Tsukahara, Y., Hoshi, H. \& Tasaki, K. (1974) Acetylcholinesterase in the retina of a marine gastropod, Haliotis discus. Tohoku J. exp. Med., 114, 141-143.

28) Yui, R. \& Fujita, T. (1986) Immunocytochemical studies on the pancreatic islets of the ratfish Chimaera monstrosa. Arch. histol. jap., 49, 369-377. 